\title{
A Museologia na web: sistema de informação sobre patrimônio cultural na era digital*
}

\begin{abstract}
Janaina Cardoso de Mello
\end{abstract}
Doutora em História Social (PPGHIS-UFRJ).PósDoutoranda em Estudos Culturais (PACCUFRJ).Professora da Graduação em Museologia da Universidade Federal de Sergipe (UFS) e dos Mestrados em História (PROHIS-UFS e PPGHUFAL)

Fabiano Conceiçao Lima Luz

Graduando em Museologia pela Universidade Federal de Sergipe (UFS). Bolsista CNPq AT-NM

Maria Márcia Crisanto Leão Montijano

Graduada em Museologia pela Universidade Federal de Sergipe (UFS).Bolsista PIBITI-UFS

Ângela Maria Ferreira de Andrade

Graduada em Museologia pela Universidade Federal de Sergipe (UFS). Bolsista PIBITI-CNPq

http://dx.doi.org/10.1590/1981-5344/1296

O artigo busca compartilhar a experiência do programa "Sistemas de Informação, cyber cultura e digitalização do patrimônio sergipano: a museologia na web" a partir da elaboração e manutenção de uma web site com um arquivo digital com entrevistas orais e captação de imagens pelos moradores mantenedores da cultura imaterial em Laranjeiras - SE. Aliada a essa produção de equipamentos culturais digitais para a área de Ciências Sociais Aplicadas estão dois subprojetos centrados na utilização de softwares livres para a organização de um banco de dados com textos sobre museologia, memória e patrimônio disponibilizados online e a criação de um dicionário eletrônico de termos museológicos a ser utilizado como ferramenta de pesquisa, base conceitual e conteúdo facilitador da relação ensino-aprendizagem nos cursos de museologia. Para os cursos graduação em Museologia tais iniciativas enquadram-se como inovação

\footnotetext{
* Pesquisa realizada com Bolsas CNPq AT-NM/ PIBITI-CNPq e UFS/Apoio: CINTTEC-UFS e FAPITEC-SE.
} 
tecnológica na área prioritária de Tecnologia da Informação.

Palavras-chave: Informação; Cybercultura; Patrimônio; Museologia; Sergipe.

\title{
The Museology on web: information system about cultural heritage in the digital age
}

\begin{abstract}
The article aims to share the experience of the program "Information systems, cyber culture and digitization of heritage in Sergipe: museology on the web" from the elaboration and maintenance of a web site with a digital file with oral interviews and capture images by locals immaterial culture maintainers in Laranjeiras - Allied to this is producing digital cultural facilities in the area of applied social sciences are two sub-projects focusing on the use of free software for the organization of a database with texts on museology, memory and patrimony available online and the creation of an electronic dictionary of terms as a museum to be used as a tool for searching, conceptual basis and content facilitator of teaching-learning ratio in museology. For undergraduate courses in Museology such initiatives fit as technological innovation in the priority area of information technology.
\end{abstract}

Keywords: Information; Cyberculture; Patrimony; Museology; Sergipe.

Recebido em 29.06.2012 Aceito em 21.01.2015

\section{Introdução}

O mundo cultural não é só produzido coletivamente, como também permanece real em virtude do conhecimento coletivo. Estar na cultura significa compartilhar com outros de um mundo particular de objetividades (BERGER, 1985, p. 23).

Os museus usualmente iniciaram sua tradição como gabinetes de curiosidades, cujo colecionismo de diversas matizes se consolidava. Na década de 1970, o Movimento da Nova Museologia se organizou a partir de vários encontros na América Latina para repensar a noção e atuação dos museus, concebendo-os em sua interação com a sociedade e trazendo 
ao seu interior a demanda de grupos sociais fora dos círculos de poder ou da burocracia estatal (FERNANDES, 2006). Homens e mulheres comuns passaram a ter vez e voz nas discussões dos projetos museológicos. A museologia social, na Declaração de Santiago do Chile em 1972, afirmava:

[...] o museu é uma instituição a serviço da sociedade, da qual é parte integrante e que possui nele mesmo os elementos que Ihe permitem participar na formação da consciência das comunidades que ele serve; que ele pode contribuir para 0 engajamento destas comunidades na ação, situando suas atividades em um quadro histórico que permita esclarecer os problemas atuais, isto é, ligando o passado ao presente, engajando-se nas mudanças de estrutura em curso e provocando outras mudanças no interior de suas respectivas realidades nacionais (PRIMO, 1999).

Frente às inovações tecnológicas e a necessidade de tornar a técnica fria um processo humanizado para servir ao social, os museus apreendem os recursos digitais como meio de preservação da memória patrimonial. Um patrimônio cultural pensado e definido pela sociedade, com delimitações geográficas, temporais e significativas na manutenção de sua identidade. Inserindo-se na definição de "patrimônio digital" preconizada pela United Nations Educational, Scientific and Cultural Organization (UNESCO) em 2004, consideram-se:

[...] recursos de conhecimento ou expressão humana, seja cultural, educacional, científico e administrativo, ou abrangendo a informação técnica, legal, médica e outros tipos de informação, [que] são cada vez mais criados digitalmente, ou convertidos de sua forma analógica original à forma digital. [...] Matérias digitais incluem textos, bases de dados, imagens estáticas e com movimento, áudios, gráficos, software, e páginas WEB, entre uma ampla e crescente variedade de formatos. Eles geralmente são passageiros e requerem produção, manutenção e gerenciamento intencionais para serem preservados. Muitos desses materiais são de valor e significância duradouros, e por isso constituem um patrimônio que deve ser protegido e preservado para a geração atual e futura. Esse patrimônio existe em qualquer língua, parte do mundo, e em qualquer área do conhecimento e expressões humanos (UNESCO, 2004).

Terra da Taieira, do Lambe Sujo e Caboclinhos (ALENCAR, 2003), Laranjeiras é uma cidade rica em manifestações da cultura imaterial, mas também possui um centro histórico e é uma "cidade-patrimônio" que na 
rota do projeto Monumenta ${ }^{1}$ traz em seu entorno as marcas do passado revitalizado os desafios do convívio humano com a preservação da arquitetura restaurada, prefigurando "o antigo que se faz novo". No ano de 2007, com a implementação de um campus da Universidade Federal de Sergipe (UFS) na cidade - com cursos de graduação em Museologia, Arquitetura, Arqueologia, Dança e Teatro - tornou-se imperativo o desenvolvimento de projetos que aliassem a tradição ancestral às novas tecnologias da modernidade, possibilitando um retorno social à comunidade que abrigara a academia.

Laranjeiras estruturou-se no século XVIII, tendo surgido às margens do rio Cotinguiba, cujas memórias locais remontam um pé de laranjeira sob o qual os viajantes descansavam protegendo-se do sol e entoando canções românticas até que chegasse o momento de se porem na estrada novamente. Para além das versões poéticas, a cidade afirmou-se como uma das principais rotas comerciais de Sergipe Del Rey, obtendo da produção canavieira sua principal fonte de renda (SILVA; NOGUEIRA, 2009, p. 40).

Elevada a condição de Vila em 07 de agosto de 1832, Laranjeiras em 1824 já era a povoação mais rica da província de Sergipe possuindo mais de sessenta engenhos de açúcar, fábricas de charutos, aguardente e representações comerciais européias. Em 4 de maio de 1848 passou a condição de cidade. De acordo com Beatriz Góis Dantas (1972, p. 17), com a instalação da Alfândega de Sergipe a localidade e a demografia se transformaram em "importante empório comercial cuja feira 'concorriam comboios de quase todos os pontos da província' comunicando-se diretamente com as capitais da Bahia, Rio de Janeiro e Pernambuco".

A urbanização do século $X X$ moveu as famílias tradicionais com poder aquisitivo para a nova capital Aracaju. Permaneceu em Laranjeiras a população de baixa renda, dependente do trabalho nas lavouras de cana-de-açúcar, vivenciando a deterioração do patrimônio arquitetônico por descaso governamental, todavia mantendo a cultura imaterial local.

Assim, embora conserve sua arquitetura vernacular, fruto da colonização portuguesa, Laranjeiras também caracterizou-se pela confluência de etnias negra e indígena com ricas manifestações populares, revelando resistência e vitalidade, apresentadas anualmente no Encontro Cultural. O Encontro Cultural de Laranjeiras foi criado em 1976 com a finalidade de estudar, pesquisar e divulgar o folclore $e$ as diversas manifestações populares locais, ocorrendo sempre no período dos festejos de Santos Reis, em janeiro (BOMFIM, 2009).

Logo, o Programa "Sistemas de Informação, cyber cultura e digitalização do patrimônio sergipano: a museologia na web", desenvolvido no Núcleo de Museologia e mantido pelo Grupo de Estudos e Pesquisas em Memória e Patrimônio Sergipano (GEMPS/CNPq), articulou

\footnotetext{
${ }^{1}$ O Programa Monumenta foi um programa do governo federal brasileiro executado pelo Ministério da

Cultura e patrocinado pelo Banco Interamericano de Desenvolvimento (BID) que consistiu na reforma e resgate do patrimônio cultural urbano em todo Brasil. Criado em 1995, atendeu mais de 26 cidades.
} 
várias ações, iniciadas em 2010 e planejadas para o decurso de três anos, direcionadas à pesquisa e elaboração de produtos tecnológicos.

Subdividido em três etapas, a primeira buscou pesquisar os modos de apreensão da população de Laranjeiras (SE) sobre a vida em uma cidade-patrimônio e a cultura imaterial que preservam, criando um banco de dados de áudio e vídeo com entrevistas realizadas com os mantenedores da cultura imaterial e disponibilizando tais registros em uma web site.

Um projeto anterior, desenvolvido desde 2009, intitulado "Vozes do Trapiche: cultura histórica, memória e identidade em Laranjeiras (SE)", cujo objetivo era a realização de entrevistas com a comunidade circundante da área universitária, forneceu boa parte do material audiovisual. Segundo Mello e Santos (2008, p. 93):

[...] consistindo a história oral no instrumental que pode reconstituir melhor os aspectos triviais das vidas das pessoas comuns sendo utilizada para confirmar outras fontes, nos deparamos com a efemeridade de seus guardiões, em sua maioria já na terceira idade, anônimos ou ilustres esquecidos em seu próprio grupo, mas com um potencial extraordinário de rememoração.

A segunda parte integrou o projeto "Mnemosine Digital - Banco de Dados sobre Museologia e Patrimônio" contando com uma equipe interdisciplinar de alunos e professores da Museologia, Arquitetura e Ciência da Computação da UFS. O trabalho inspirou-se no Programa Prossiga $^{2}$ financiado pelo Conselho Nacional de Desenvolvimento Científico e Tecnológico (CNPq) para a manutenção de um banco de dados de áreas prioritárias ao governo federal.

No contexto da democratização das informações, da organização da Conferência Nacional da Cultura, do plano decenal de políticas culturais no Brasil a partir de 2009/2010 e da $4^{a}$ Conferência Nacional de Ciência, Tecnologia e Inovação (CNCTI) em 2010, o projeto realizado na UFS visa contribuir na formação de profissionais das Ciências Sociais Aplicadas e Ciências Humanas. É também uma ferramenta importante no quadro de ampliação da oferta de cursos de graduação em Museologia desde 2009 e contribui ainda para a inovação de processos no campo da Tecnologia da Informação de baixo custo.

O objetivo geral do projeto era a criação de um banco de dados que concentrasse, organizasse, catalogasse e sistematizasse os textos em PDF ou Word em língua portuguesa referentes à "Museologia, memória e patrimônio" (artigos, periódicos científicos, anais, dissertações e teses) disponibilizados aleatóriamente na internet.

\footnotetext{
2 Desde 1995 o Prossiga tem como objetivo promover a criação e o uso de serviços de informação na Internet para as áreas prioritárias do Governo Federal, assim como estimular o uso de veículos eletrônicos de comunicação pelas comunidades dessas áreas. O Prossiga é um programa que oferece metodologias consolidadas de organização e tratamento da informação em ambiente web. (Disponível em: <http://prossiga.ibict.br>. Acesso em: 10 set. 2010).
} 
Dentre os objetivos específicos: o desenvolvimento e a manutenção de um site próprio com banco de dados acessível a diversos segmentos culturais e educacionais, profissionais de museus, pesquisadores e interessados em temas do patrimônio cultural em língua portuguesa; a formação nos alunos de Museologia de habilidades e competências no manuseio de softwares livres e ferramentas tecnológicas em seu ofício; o estímulo ao trabalho em equipe interdisciplinar; a atualização continuada de alunos e profissionais das áreas das Ciências Humanas e Sociais Aplicadas e o incentivo ao uso das tecnologias por funcionários de instituições museais no Estado de Sergipe, tendo em vista que:

Os museus são espaços destinados à reunião de objetos de variadas tipologias, que, ao serem identificados e contextualizados, expressam um determinado fato histórico, social e cultural. Constituído a partir de um interesse pelas coisas, como indica Burke (2003), os museus, pela sua organização, criam uma narrativa sobre os objetos expostos, que permite aos indivíduos a construção do conhecimento sobre um determinado assunto ou determinada época (PADILHA; CAFÉ; SILVA, 2014, p. 69).

Preocupando-se com a disseminação mais ampla do conhecimento museal, a terceira parte pretendeu desenvolver um sistema de hipertexto em ambiente computacional para implementação de um dicionário eletrônico de termos museológicos denominado Véritas Mouseion, a ser disponibilizado para livre acesso por estudantes e profissionais da Museologia e áreas afins. O uso da lingüística como produtora de sentido nos termos selecionados partiu do pressuposto de que:

[...] pela extensão do vocabulário e pela fertilidade de seus elementos na qual se incluem dois modos operantes: o fixo, em que a palavra é a base da construção limitada, restrita, e o flexível, em que as palavras têm múltiplas definições e são dotadas de combinações associativa (MENDONÇA, 2000, p. 50).

Como norte, a compreensão de que as palavras são conceitos culturalmente construídos por discursos - partindo "de quem fala", "do lugar de onde fala" e "para quem se fala" - definidos e ressignificados ao longo do tempo, espaço e demografia. Por isso, o Véritas Mouseion adotou como modus operandi "do lugar de fala" na elaboração de seu vocabulário com "múltiplas definições e combinações associativas".

Embora audacioso e com várias frentes ocorrendo paralelamente, o programa e os subprojetos que a ele se integraram possuem um expressivo quantitativo de alunos bolsistas e voluntários do curso de Museologia, professores multidisciplinares, além de estrutura física e operacional do curso de Ciências da Computação, responsável pelo 
desenvolvimento dos bancos de dados. Inserindo-se nesse contexto uma docente do Núcleo de Arquitetura, que se encarregou também pelo auxílio tecnológico na web.

\section{Da gestão de documentos aos documentos como patrimônio digital}

À partir de 1970 o conceito de "gestão de documentos" (surgido nos EUA na segunda metade de século XX) começa a ser aplicado no Brasil. A Fundação Getúlio Vargas implanta um sistema de arquivos pioneiro de Maria de Lourdes Costa e Silva. Em 1980, os programas de gestão são aplicados na Casa de Rui Barbosa $^{3}$ e no Banco Nacional do Desenvolvimento econômico. ${ }^{4}$

O programa de gestão de documentos visa racionalizar as atividades do arquivo, criando condições para a preservação da memória institucional, propiciando rápido acesso às informações que sejam de interesse da repartição, do governo ou do cidadão (FANTINI, 2001). Logo, as instituições museais sentem a necessidade de incorporar esse instrumento à organização e catalogação de seu acervo.

No século XXI a Museologia tem aplicado a informatização e o aperfeiçoamento de suas bases técnicas nos Museus de Ciência e Tecnologia. O uso das tecnologias e da internet na pesquisa e melhoria de dados aliou-se à necessidade de preservação da memória na era da globalização e do esquecimento advindos da velocidade de informações produzidas pela mídia (FERNEDA, 2003). De acordo com Murguia e Ribeiro (2001, p. 185):

com a idéia de rede, todos os dados estão conectados: a partir de um é possível entrar em todos, e nenhum deles impede de se entrar nos outros. A memória-rede não precisa de uma ordem prévia, é o próprio movimento desnorteado, no sentido de fragmentado.

A necessidade de armazenar, organizar e recuperar informações é crescente na contemporaneidade. Por isso a prospecção cultural digital centra-se nos conceitos-chave "Museologia, memória e patrimônio" subdivididos nos eixos: 1. Memória, Museologia Social; 2. Patrimônio material e imaterial; 3. Museus de ciência e tecnologia, museus de arte e museus históricos; 4. Educação patrimonial e patrimônio ambiental. Isto posto que:

o museu, assumindo-se como um banco de dados concretos acessível a todos, torna-se numa escola de saber não formal, um local de encontro com o público, um sítio particularmente

\footnotetext{
${ }^{3} \mathrm{O}$ acesso às bases de dados pode ser feito via: <http://www.casaruibarbosa.gov.br/interna.php?ID_S=6>. Acesso em: 18 jan. 2011.

${ }^{4}$ As bases de dados podem ser acessadas em:

<http://www.bndes.gov.br/SiteBNDES/bndes/system/modules/br.gov.bndes.prototipo/templates/tmp_resu Itado_busca.jsp>. Acesso em: 18 jan. 2011.
} 
propício à criação de novas formas culturais, novas relações sociais e novas soluções para os problemas existenciais que afetam os indivíduos e as comunidades". (ROQUE, 1989/90, p. 25)

Canclini (1994) ao ampliar a noção de patrimônio cultural para além de monumentos arquitetônicos, percebe-o também como uma rede de solidariedades, ou seja, um lugar de cumplicidade social que não tem por fim último perseguir a autenticidade, mas reconstituir a verossimilhança histórica através de linguagens, conhecimentos, tradições e modos de usar os bens e espaços físicos. Nesse sentido, os espaços virtuais constituem linguagens tecnológicas em rede capazes de guardar e socializar os registros do patrimônio cultural de forma mais ampla e acessível.

Thompson (1992) já havia detectado o valor das fontes orais na história social moderna, uma vez que a oralidade proporciona presença histórica e reconhecimento àquelas pessoas cujos pontos de vista e valores foram descartados pela 'história vista de cima' na vigência da hegemonia de dados rankeana que privilegiou o registro oficial das ações políticas dos representantes da hierarquia sócio-econômica e cultural. ${ }^{5}$ Desse modo, a fala de populações comuns compartilhando seu cotidiano cultural online ressignifica as relações sociais.

Para Santana (2000, p. 51), a construção da cidadania, garantindo uma "cidade-cidadã", não pode prescindir da construção e preservação da memória dos grupos, uma vez que ao abrir espaços para a inclusão de novos patrimônios a cidadania produz sua memória.

As tecnologias da informação possibilitam organizar e conservar a noção de "documento ampliado" ressaltado por Jacques Le Goff (1984), em seus distintos formatos manuscritos, sonóros e imagéticos.

Dessa forma a teoria e a prática aliam-se para possibilitar idéias que ensejem melhores condições de vida para universidade e comunidade extra-muros em Laranjeiras. Ao mesmo tempo em que as vozes da população fora da orbis acadêmica, enquanto registros de seus modos de ver e viver, são valorizadas e compreendidas como essenciais aos estudos dos alunos intra-muros universitários cuja cultura é seu objeto de formação intelectual e profissional. O uso das tecnologias permite pinçar informações qualitativas e quantitativas para a compreensão da memória social como patrimônio digital ensejando uma realidade social intercambiante.

A organização de um site específico que acondicione em um único lugar o conhecimento formal $e$ informal torna-se uma ferramenta

\footnotetext{
${ }^{5}$ Referência ao historiador alemão Leopold Von Ranke (1795 - 1886) que elaborou métodos básicos para uma "História Científica". Os historiadores do século XIX consideravam como fontes primárias apenas documentos escritos oficiais, produzidos pelo Estado. Os documentos conteriam "a verdade", sendo função do historiador apenas reproduzir os fatos descritos. Essa linha teórica ficou conhecida como historicismo alemão, sendo influenciada diretamente pelo Romantismo.
} 
imprescindível tanto na relação ensino-aprendizagem quanto na compreensão do patrimônio cultural e suas interfaces museológicas.

\section{A Museologia na era digital: do fazer ao saber}

A Museologia como um campo interdisciplinar por excelência agrega pesquisadores de diversas áreas e busca metodologias que possam auxiliar na pesquisa formativa de seus profissionais, bem como na realização de sua expografia. Adaptar uma metodologia já reconhecida em um projeto requer cuidados, mas também a quebra com os limites de usos restritos ao ideal para a qual foi concebida.

Assim, o método utilizado dividiu-se em três fases paralelas: a primeira condicionada às linguagens computacionais da contemporaneidade e a segunda norteada pela área das Ciências Humanas e Sociais Aplicadas.

A primeira fase (digitalização do patrimônio Sergipano) compreendeu um aprofundamento teórico-metodológico da equipe multidisciplinar do projeto sobre os estudos de patrimônio, a memória e a oralidade, a necessidade de preservação e acesso a ele, seguindo-se os passos de Alberti (2004). A partir do material em arquivo MP-3 obtido nas entrevistas junto aos portadores de memória e mantenedores da cultura imaterial na comunidade de Laranjeiras (SE) foi realizada a digitalização do material autorizado, organização do arquivo de áudio e imagem, criação do protótipo de uma web site para disponibilizar a "Memória Oral de Laranjeiras (SE)" e inserção do material digitalizado nesse suporte tecnológico.

A segunda fase (Cyber cultura museológica) abrangeu leitura teórica e aprendizado tecnológico sobre o processo de construção de um banco de dados. Posteriormente foi colocada em prática pelos alunos de Ciência da Computação a elaboração de um banco de dados relacional por meio da modelagem conceitual, modelando o projeto físico e em seguida empreendendo a esquematização do projeto lógico, adaptando-o às características de softwares livres como MySQL, Apache e PHP (HEUSER, 1998; KORTH; SILBERSCHATZ, 1994; TEOREY,1994).

Aos alunos de Museologia coube levantar, selecionar e catalogar em áreas temáticas o material disponibilizado na internet sobre patrimônio. Também recorreu-se ao site do Instituto do Patrimônio Histórico e Artístico Nacional (IPHAN), junto ao sistema de classificação das tipologias patrimoniais contidas no Inventário Nacional de Referências Culturais (INRC). ${ }^{6}$ Sobretudo, buscaram respeitar a denominação tipológica dada pelos próprios autores aos assuntos discutidos nos textos selecionados. Para tanto foi elaborada uma ficha de coleta de dados e o trabalho embora envolvesse uma considerável quantidade de textos dispersos aleatóriamente na internet e de livre acesso, foi feito com relativa rapidez.

${ }^{6}$ Disponívelem:<http://www3.iphan.gov.br:8080/interfacePublicaInrc/paginas/principal/principal.seam;jsessioni $\mathrm{d}=$ CDB49C05152F7D8BCEE321B572C7406C >. Acesso em: 16 nov. 2010. 
Ficha de Coleta de Dados

\begin{tabular}{|l|}
\hline Título: \\
\hline Autor: \\
\hline ( )artigo ( )monografia ( )dissertação ( )tese ( ) outros \\
\hline Procedência institucional: \\
\hline Quantidade de Páginas: \\
\hline Resumo (5 linhas): \\
\hline Palavras-chave (3): \\
\hline Link de acesso: \\
\hline Data de acesso: \\
\hline
\end{tabular}

Utilizou-se a "etnografia informacional" para navegar no ciberespaço aplicando a observação, seleção, registro e conceituação dos objetos, fenômenos e acontecimentos presentes no ciberespaço e que compondo um quadro síntese elaborado previamente venha a representar, temporária e circunstancialmente, o campo do patrimônio digital. Uma vez que:

uma etnografia informacional é desenvolvida para a observação de fragmentos informacionais (memórias digitais) na Internet, tendo como foco inicial da rede de referências e citações a campanha internacional da UNESCO para salvaguardar a memória digital e delinear as linhas mestras para a preservação do patrimônio digital mundial. A construção/moldura (em oposição à identificação/recorte) do universo conceitual relacionado à idéia de patrimônio digital fará uso da navegação hiperbólica (software livre HiperEditor), a qual permite, no espaço da tela, incluir e navegar na representação conceitual construída. (DODEBEI, 2005).

A alimentação do banco de dados foi realizada pelos bolsistas de Museologia e a coordenação do projeto, com o suporte do Departamento de Ciência da Computação. A elaboração, criação e hospedagem de uma web site (via hostnet) para o acondicionamento do banco de dados ficou sob responsabilidade da professora do curso de Arquitetura e também coordenadora do Laboratório de Informática no Campus da UFS Laranjeiras.

A construção de uma "rede de memórias virtuais" para determinado foco temático não poderá prescindir de um conhecimento já construído, ao menos na perspectiva do interessado, e é esse conhecimento que deve também guiar a navegação, corrigindo seu rumo. Para facilitar o acesso aos dados alocados no site, a "síntese informacional" propôs-se à construção de uma rede de conceitos-chave que delimitam o campo de busca ou consistem no foco desejado. 
O gerenciamento e alimentação do banco de dados, de caráter contínuo, tem sido realizado segundo as normatizações específicas da área da Ciência da Computação e Ciência da Informação (MACEDO, 2003).

Por fim, na terceira etapa (Sistemas de informação museológica) realizou leituras teóricas e aprendizado tecnológico sobre a construção de um dicionário eletrônico. Após a identificação da evolução da terminologia museológica de língua portuguesa está sendo realizada a classificação dos termos museológicos em grandes áreas conceituais. Para a elaboração da arquitetura de informação do dicionário eletrônico são considerados: o nível da apresentação (interface com o usuário), o nível da máquina abstrata de dados (ligações) e o nível da base de dados (armazenamento e gerenciamento). Será realizado um estudo das ferramentas de modelagem conceitual para a implementação do dicionário eletrônico.

As informações coletadas para compor os verbetes do dicionário provém dos textos que estão sendo acondicionados no banco de dados Mnemoisine Digital, e também de questionários/entrevistas submetidos a museólogos do Brasil e de Portugal sobre as definições dos termos em língua portuguesa, a partir da ficha abaixo discriminada:

\section{Ficha de Dados - Verbete}

\begin{tabular}{|l|}
\hline Termo: \\
\hline Definição: \\
\hline Referências: \\
\hline Colaborador: \\
\hline Procedência institucional: \\
\hline Data: \\
\hline
\end{tabular}

\section{Apresentação e discussão dos resultados}

Da primeira etapa, até o presente momento conta-se com 4 CD's e 1 DVD com 75 entrevistas realizadas em Laranjeiras (SE) com homens e mulheres com idade entre 15 anos e 65 anos. Dentre os entrevistados estão estudantes, funcionários públicos e empregados do setor privado (ativos e aposentados).

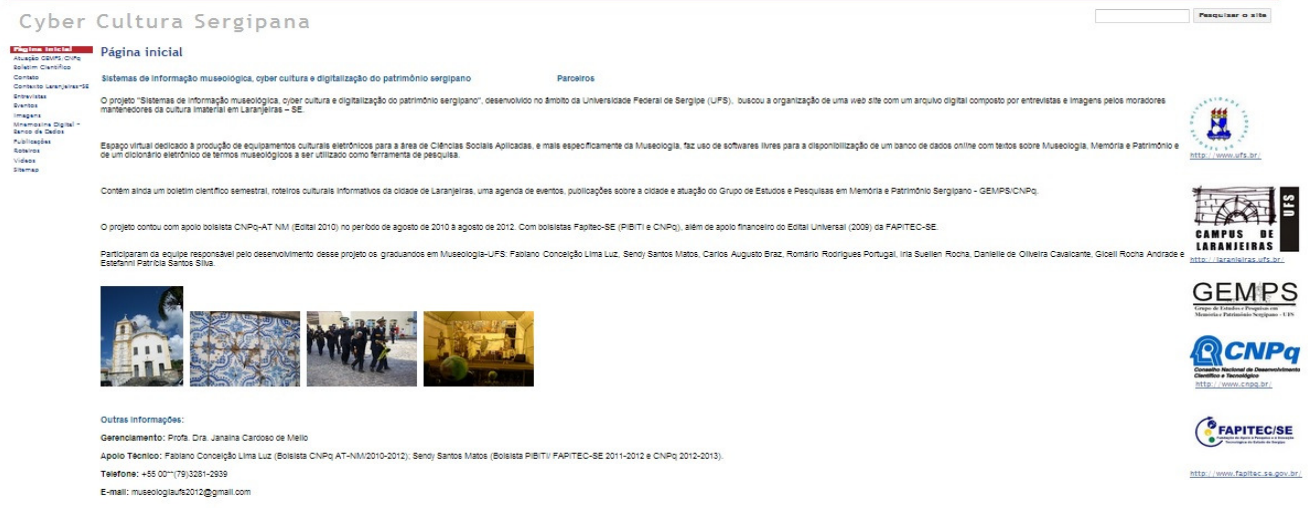

FIGURA 1 - Layout da website Cyber Cultura Sergipana

Fonte: <https://sites.google.com/site/cyberculturasergipana>. Acesso em: 20 jan. 2015. 
O site "Cyber Cultura Sergipana" traz de forma simplificada doze interfaces com o usuário. Na "página inicial" há a apresentação do projeto, financiadores, equipe participante e logos intitucionais. Na interface "atuação do GEMPS/CNPq" é apresentado o grupo de pesquisa que atua diretamente nas pesquisas e alimentação do site, há ainda um link que direciona para o blog específico do grupo. Há um "Boletim Científico" com um pequeno informativo de duas páginas, publicado semestralmente, contendo notícias, eventos, entrevistas e trechos de relatórios de projetos de pesquisa em curso. Há também endereço e email para "contato".

Nas demais interfaces encontram-se o "contexto de Laranjeiras-SE" abordando sua localização geográfica, seu histórico e manifestações culturais imateriais composta por grupos folclóricos e folguedos tradicionais, além da Micarême, um carnaval local criado na década de 1930. No áudio das "Entrevistas" os moradores expõem sua visão de patrimônio, cultura, cidade, economia local e presença da UFS em Laranjeiras. Os "eventos" que ocorrem na cidade são destacados e há também imagens de igrejas e capelas, manifestações culturais e museus.

Verificou-se que Laranjeiras abriga muitos "forasteiros", ou seja, pessoas que não nasceram na cidade, mas que nela residem há mais de 30 anos. Dentre a formação escolar há pessoas sem qualquer tipo de alfabetização e outras com terceiro grau completo ou incompleto.

Percebe-se o apreço dos moradores pela cidade e embora muitos não reconheçam o "patrimônio cultural" em seus conceitos formais e acadêmicos, a grande maioria valoriza a antiguidade dos prédios da cidade, ressaltando seu valor histórico e reivindica a restauração daqueles edifícios em ruínas no calçadão e na praça Possidônia Bragança. Porém, chocam-se com os organismos estatais ou federais que lhes impedem a livre-circulação ou o uso dos bens que em sua compreensão são de caráter privado (a exemplo da proibição de alterações nas fachadas de suas residências).

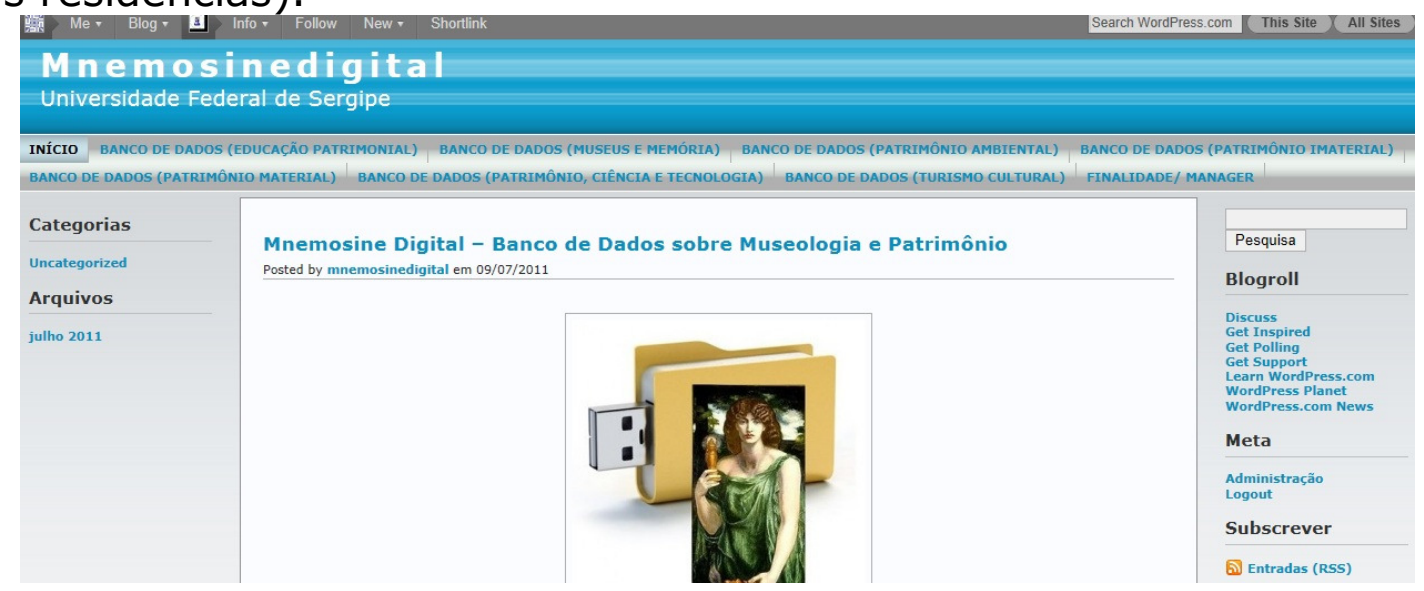

FIGURA 2 - Layout da website Mnemosine Digital

Fonte: <http://mnemosinedigital.wordpress.com>. Acesso em: 20 jan. 2015. 
a) Da segunda etapa, até a presente data foram selecionados, organizados, classificados e registrados os links de 350 textos cujas abordagens focam:

b) Patrimônio Imaterial: Lambe-sujo e caboclinho, Dança de São Gonçalo do Amarante, Folguedos, Samba de Pareia do Mussuca, Danças gaúchas, comidas típicas.

c) Patrimônio Material: capelas, igrejas, casarios, Trapiche, engenhos, cidades, favelas, escolas, indústrias, ruínas, artefatos arqueológicos, arte na República, arte no Império, arte na Colônia. cultura.

d) Patrimônio Ambiental: Gestão ambiental, Parques ecológicos e

e) Educação Patrimonial: A escola e o Museu, Educação Patrimonial nos Museus de São Paulo. Sergipe.

f) Turismo Cultural: Turistas no Museu, Turismo étnico, Turismo em

g) Patrimônio, Ciência e Tecnologia: Ciência nas exposições, Memória e patrimônio virtual, Museus e Centros de Ciência, carta de preservação do patrimônio digital.

h) Museus e Memória: Anais da Casa de Rui Barbosa, estratégias de museus no século XXI, MAX, Museologia em Portugal, Museu e recepção, Museus de Artes e Ofício, Museus e negritude, Museus infantis, Promoção de Museus, Teoria da Museologia, Comunicação nos Museus, Como gerir um Museu, Declaração de Quebec, Declaração de Santiago do Chile, Musealização da Arqueologia, Museu de Angola, Museu local, Museus no Rio Grande do Sul, Oficina de Expografia, Acessibilidade em Museus, Museus de Sergipe, Memória em Pollack.

\begin{tabular}{|c|c|c|}
\hline 解Painel & (10) Mnemosinedigital & Are you new here? \\
\hline Melhorias & \multirow{2}{*}{ Editar página Adicionar Nova } & Opçốes de Tela V Ajuda V \\
\hline \& Posts & & \\
\hline 畹 Midia & Banco de Dados (Educação Patrimonial) & Publicar \\
\hline Links & $\begin{array}{l}\text { Link Permanente http:/lmnemosinedigital.wordoress.com/banco-de-dados....ao-patrimonial (Editar Ver página } \\
\text { Pegar link permanente) }\end{array}$ & Visualizar alteraçōes \\
\hline [ᄂ Páginas & 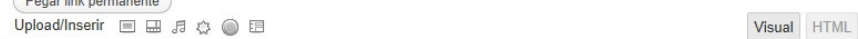 & \multirow{3}{*}{$\begin{array}{l}\text { Status: Publicado Editar } \\
\text { Visibilidade: Público Editar } \\
\text { 10 Publicado em: } 10 \text { de julho de } 2011 \text { às } \\
\text { 12:22 Editar }\end{array}$} \\
\hline $\begin{array}{l}\text { Todas as Páginas } \\
\text { Adicionar Nova }\end{array}$ & 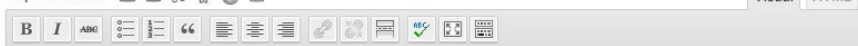 & \\
\hline Comentários & $\begin{array}{l}\text { (2) Título: O Contributo do Patrimônio Material e Imaterial na Formação do Educador de Jovens e Adultos: } 0 \\
\text { relato da Universidade Federal de Ouro Preto }\end{array}$ & \\
\hline (ㄷ) Enquetes & \multirow{3}{*}{$\begin{array}{l}\text { Autor: Fernanda Aparecida Oliveira Rodrigues Silva } \\
\text { Tipologia: ( X)artigo ( )monografia ( )dissertação ( )tese ( ) outros } \\
\text { Procedência institucional: Congresso Internacional de Alfabetizaç̃o }\end{array}$} & Mover para a lixeira \\
\hline () Votaçōes & & \\
\hline 圆 Aparência & & $\begin{array}{l}\text { Atributos de Página } \\
\text { Mãe }\end{array}$ \\
\hline 88 Usuários & \multirow{4}{*}{ 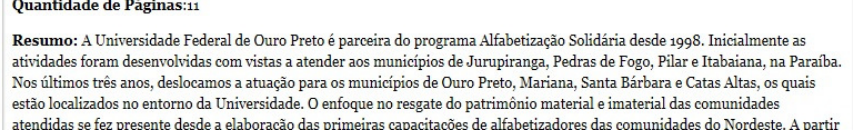 } & (sem mãe) \\
\hline If Ferramentas & & Modelo \\
\hline (89) Configuraçöes & & Modelo Padrão \\
\hline (4) Recolher menu & & \\
\hline
\end{tabular}

FIGURA 3 - Layout da website Mnemosine Digital

Fonte: <http://mnemosinedigital.wordpress.com>. Acesso em: 20 jan. 2015.

Com relação à terceira etapa, já estão catalogados 80 termos museológicos com suas respectivas definições, como pode ser visualizado na tabela abaixo: 
TABELA 1 - Termos Museológicos (Dicionário Véritas Mouseión)

\begin{tabular}{|c|c|c|}
\hline Entrevistado & Área de atuação & Verbetes \\
\hline Verônica Maria M. Nunes & $\begin{array}{lcr}\text { Historiadora e } & \text { Museóloga. } \\
\text { Diretora do Museu do Homem } \\
\text { Sergipano } & \text { (MUHSE) em } \\
\text { Aracaju/ SE } & & \end{array}$ & $\begin{array}{l}\text { Objeto Museológico: "é um artefato da } \\
\text { sociedade, produto do próprio homem, e } \\
\text { que foi feito para satisfazer as } \\
\text { necessidades do presente". } \\
\text { Reserva Técnica: "são espaços de } \\
\text { gurada de todos os objetos museológicos } \\
\text { que não estão em exposição [...]". } \\
\text { Coleção: "é a ordenação de um grupo de } \\
\text { objetos a partir da procedência[...]". }\end{array}$ \\
\hline Ludmilla Silva de Oliveira & 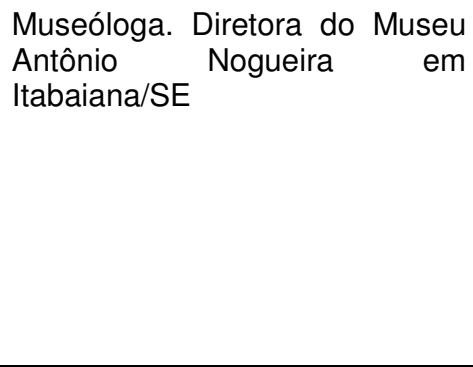 & $\begin{array}{l}\text { Diorama: "é uma representação artística } \\
\text { que tenta dar um ar de realismo a um } \\
\text { determinado contexto, pode ser uma } \\
\text { paisagem ou um momento histórico [...]". } \\
\text { Croqui: "[...] é um desenho, um rabisco, } \\
\text { um esboço [...] de uma ideia instantânea, } \\
\text { para que não se perca a ideia". } \\
\text { Curador: "é o profissional responsável } \\
\text { pela concepção, montagem e exposição } \\
\text { de determinadas obras [...]". }\end{array}$ \\
\hline $\begin{array}{l}\text { Vera Lúcia Cardin de } \\
\text { Cerqueira }\end{array}$ & $\begin{array}{l}\text { Socióloga da SECULT/SP e } \\
\text { funcionária do Pavilhão das } \\
\text { Culturas Brasileiras em São } \\
\text { Paulo }\end{array}$ & $\begin{array}{l}\text { Exposição: "é um recorte, uma narrativa } \\
\text { no espaço, feita a partir de alguns } \\
\text { registros ou objetos". } \\
\text { Coleção: "é um conjunto de registros, } \\
\text { objetos que fazem parte de uma mesma } \\
\text { temática ou tem algum eixo significativo } \\
\text { [...]". } \\
\text { Acervo: "pode ser um conjunto de } \\
\text { objetos ou de registros que pode deter } \\
\text { diferentes coleções, ou seja, diferentes } \\
\text { conjuntos em si [...]". }\end{array}$ \\
\hline
\end{tabular}

Fonte: Tabela elaborada pela graduanda de Museologia Joelma Dias Matias (2012).

Percebe-se que o modo como a informação circula e é apropriada na contemporaneidade propicia nomeações e renomeações para objetos já existentes na sociedade, mais especificamente, na sociedade da informação concretizada no século XX.

A rede de conhecimentos digitais pode indicar uma melhor organização da representação e constituição de uma estrutura conceitual pressupondo a identificação e a segmentação do domínio do conhecimento considerado o foco, a fim de poder efetuar a análise de seus fragmentos ou conceitos singulares. Uma vez que: 
passou-se ao mesmo tempo do suporte papel para o suporte eletrônico e da contemplação individual ou colectiva, mas monotópica, à contemplação universal e mundial (DESVALLÉES,2003, p. 18).

O patrimônio digital é, sobretudo, uma construção social, na qual os seres humanos e suas ações no tempo e no espaço constituem a grande riqueza documentada. Não representa algo acabado, é uma estrutura que vai sendo montada por grandes ou pequenos públicos. Paradoxalmente, trata-se de uma cultura dita globalizada, ao mesmo tempo em que se busca 0 reconhecimento da cultura de pequenos grupos, 0 compartilhamento e a troca de heranças e línguas em vias de desaparecimento em meio a um processo de virtualização e subjetividade cada vez maiores (CAVALCANTE, 2007, p.164).

Esses resultados apontam a possibilidade de aplicação dos indicadores de memória na salvaguarda do patrimônio cultural e comunicação museológica para além das peças ou objetos que compõem os acervos museológicos.

\section{Considerações finais}

Neste estudo, a difusão de informações sobre a memória coletiva e o patrimônio cultural de Laranjeiras (SE) através de uma website, foi examinada com o propósito de se aliar a produção universitária da pesquisa museológica ao campo da Gestão da Informação e do Conhecimento (GIC), no contexto da Ciência da Informação (CI). Segundo Duarte (2011):

no domínio das Ciências Sociais Aplicadas, a CI acompanha os processos de estudo das sociedades e dos indivíduos que as compõem e está sensibilizada aos diferentes modos de olhar e de entender o funcionamento das estruturas e das relações sociais. Uma das características da CI é a interdisciplinaridade, para tentar resolver os problemas informacionais existentes na sociedade, o que denota sua importância como ciência social (DUARTE, 2011, p.160).

O patrimônio mantido por um grupo social é percebido como um conceito composto por valores e julgamentos manifestos e representados em práticas e expressões culturais com todo um sistema de significados que Ihe dá um sentido próprio.

O registro de vozes comuns em Laranjeiras, mas protagonistas do espaço e tempo vivenciado, através de entrevistas, busca sua incorporação cidadã à instituição educacional que deve servir ao social e valorizar sua gente. 
A interação da Museologia com a comunidade local através da pesquisa representa não somente um avanço no conhecimento e diagnóstico das necessidades sociais, mas, sobretudo estabelece a criação de um espaço de convívio democrático e um laboratório para o exercío da prática profissional nos princípios da museologia social, preocupada não apenas com o patrimônio de pedra e cal, mas com as pessoas que dele fazem uso.

Há muito que a Museologia busca caminhos teóricos e metodológicos para organização e análise de suas fontes, recorrendo às ciências vizinhas no empréstimo de ferramentas interpretativas. Mas para além de tornar seu ofício dependente, a ressignificação de experiências já bem sucedidas, adaptadas à sua realidade possibilita novos caminhos na perspectiva do gerenciamento de documentação na contemporaneidade.

Apesar das especificidades teóricas e metodológicas das áreas da Ciência da Informação, da Ciência da Computação e da Museologia a elaboração de um sistema de gestão de informação virtual dos dados coletados via pesquisa acadêmica junto à comunidade da cidade de Laranjeiras (SE) permite estabelecer um diálogo interdisciplinar compartilhado na promoção do patrimônio cultural de uma determinada população.

Mais do que classificar, catalogar e expor, o trabalho do museólogo enquanto um pesquisador que investiga e é capaz de compreender o produto da coleta de dados que realiza confere um diferencial em sua formação e aperfeiçoamento profissional. Mais do que um técnico, ao desenvolver um olhar atento sobre a realidade e a sociedade que o cerca, assume para si a participação na construção e divulgação do conhecimento. Esse é seu fazer, esse é seu saber.

\section{Referências}

ALBERTI, V. Manual de história oral. 2. ed. Rio de Janeiro: FGV, 2004.

ALENCAR, A. D. F. de. Danças e folguedos. Iniciação do Folclore Sergipano. 2. ed. Aracaju: Edições do Autor, 2003.

BERGER, P. L. O dossel sagrado: elementos para uma teoria sociológica da religião. São Paulo: Paulinas, 1985.

BOMFIM, W. de J. Notas sobre o Encontro Cultural de Laranjeiras. In: SILVA, E. D. da; NOGUEIRA, A. D. (Orgs.) O despertar do conhecimento na colina azulada: a Universidade Federal de Sergipe em Laranjeiras. São Cristóvão: EdUFS, 2009. v. 2. p.113-130.

CANCLINI, N. G. O patrimônio cultural e a construção imaginária do nacional. Revista do Patrimônio Histórico e Artístico Nacional, n. 23, p. 95$115,1994$.

CAVALCANTE, L. E. Patrimônio digital e informação: política, cultura e diversidade. Enc. Bibli: R. Eletr. Bibliotecon. Ci. Inf., Florianópolis, n. 23, p. $152-170,10$ sem. 2007. 
DANTAS, B. G. A Taieira de Sergipe: uma dança folclórica. Petrópolis: Vozes, 1972.

DESVALLÉES, André. Que futuro para os museus e para o patrimônio cultural na aurora do terceiro milênio? In: ENCONTRO APOM, novembro de 2001, Casa da Eletricidade, Funchal. [Conferência]. Tradução de João Carlos Brigola - Universidade de Évora]. Revista da APOM, n.1, p. 46-74, out. 2003.

DODEBEI, V. Patrimônio digital: foco e fragmento no movimento conceitual. In: ENCONTRO NACIONAL DE CIÊNCIA DA INFORMAÇÃO, 6., 2005, Salvador. Anais... Salvador: UFBA, 2005. Disponível em: <http://www.cinform.ufba.br/vi_anais/docs/VeraDodebei.pdf>. Acesso em: 14 set. 2009.

DUARTE, E. N. Conexões temáticas em gestão da informação e do conhecimento da ciência da informação: proposta de redes humanas. Inf. \& Soc.: Est., v. 21, n. 1, p. 159-173, 2011.

FANTINI, S. R. Aplicação do gerenciamento eletrônico de documentos. 2001. Dissertação (Mestrado em Ciência da Informação) - Universidade Federal de Santa Catarina, Santa Catarina, 2001.

FERNANDES, A. M. S. Um núcleo documental para o estudo do MINOM. 2006. Disponível em: <www.minom.com>. Acesso em: 27 mar. 2010.

FERNEDA, E. Recuperação de informação: análise sobre a contribuição da ciência da computação para a CI. 2003. Tese (Doutorado em Ciência da Informação) - Universidade de São Paulo, São Paulo, 2003.

HEUSER, C. A. Projeto de banco de dados. Porto Alegre: Sagra DCLuzzato, 1998.

KORTH, H; SILBERSCHATZ, A. Sistemas de bancos de dados. São Paulo: Makron Books, 1994.

LE GOFF, J. História e memória. Lisboa: Edições 70, 2000. v. 1 e 2.

MACEDO, G. M. F. Bases para implantação de um sistema de gerenciamento eletrônico de documentos (GED). 2003. Dissertação (Mestrado em Ciência da Informação) - Universidade Federal de Santa Catarina, Santa Catarina, 2003.

MELLO, J. C. de; SANTOS, R. da S.. Memória e identidade alagoana: a oralidade na constituição do patrimônio cultural do Estado. Revista Saeculum, v. 18, p. 91-103, 2008.

MENDONÇA, E. S. A linguística e a ciência da informação: estudos de uma interseção. Ci. Inf., Brasília, v. 29, n. 3, p. 50-70, set./dez. 2000.

MURGUIA, E. I.; RIBEIRO, R. D. do P. Memória, história e novas tecnologias. Impulso, v. 12, n. 28, p.178-188, 2001. 
PADILHA, R. C.; CAFÉ, L.; SILVA, E. L. da. O papel das instiuições museológicas na sociedade da informação/conhecimento. Perspectivas em Ciência da Informação, v. 19, n. 2, p. 68-82, abr./jun. 2014.

PRIMO, J. Museologia e patrimônio: documentos fundamentais - organização e apresentação. Cadernos de Sociomuseologia, n. 15, p. 95-104, 1999.

ROQUE, M. I. R. A comunicação no museu. 1989/90. Dissertação (Mestrado em Museologia e Patrimônio Artístico) - Universidade Lusíada de Lisboa, Lisboa, 1990.

SANTANA, M. A. Memória, cidade e cidadania. In: COSTA, I. T. M.; GONDAR, J. Memória e Espaço. Rio de Janeiro: 7Letras, 2000. p. 44-53.

SILVA, E. D. da; NOGUEIRA, A. D. Lançando um olhar sobre o patrimônio arquitetônico de Laranjeiras. In: NUNES, V. M. M.; NOGUEIRA, A. D. (Orgs.). O despertar do conhecimento na colina azulada: a Universidade Federal de Sergipe em Laranjeiras. 2. ed. São Cristóvão: EdUFS, 2009. v. 1

TEOREY, T. J. Database modeling \& design: the fundamental principles. San Francisco, CA: Morgan Kaufmann, 1994.

THOMPSON, P. A voz do passado: história oral. São Paulo: Paz e Terra, 1992.

UNESCO. Carta sobre a preservação do patrimônio digital. Global, 23/07/2004. Disponível em: <http://osi.unesco.org.br/arquivos/documentos/UNESCO\%20Carta\%20Pr eservacao\%20Digital_PT\%20final.pdf>. Acesso em: 28 out. 2010. 